\title{
Single Cell RNA Sequencing Identifies IGFBP5 And QKI In Ciliated Epithelial Cell Genes Associated With Severe COPD
}

\section{Xiuying Li}

University of Pittsburgh

Guillaume Noell

Insitut d'investigations Biomediques August Pi i Sunyer

Tracy Tabib

University of Pittsburgh

Alyssa D Gregory

University of Pittsburgh

Humberto E Trejo Bittar

University of Pittsburgh

Ravi Vats

University of Pittsburgh

Tomasz Kaminski

University of Pittsburgh

John Sembrat

University of Pittsburgh

Mark E Snyder

University of Pittsburgh

Divay Chandra

University of Pittsburgh

Kong Chen

University of Pittsburgh

Chunbin Zou

University of Pittsburgh

Yingze Zhang

University of Pittsburgh

Prithu Sundd

University of Pittsburgh

John F McDyder

University of Pittsburgh

Frank Sciurba 
University of Pittsburgh

\section{Mauricio Rojas}

University of Pittsburgh

\section{Robert Lafyatis}

University of Pittsburgh

\section{Steven D Shapiro}

University of Pittsburgh

\section{Rosa Faner}

Institut d'Investigacions Biomediques August Pi i Sunyer

\section{Toru Nyunoya ( $\sim$ nyunoyat@upmc.edu )}

University of Pittsburgh School of Medicine https://orcid.org/0000-0002-0688-4607

\section{Research}

Keywords: single cell RNA-seq, COPD, cigarette smoke

Posted Date: November 4th, 2020

DOI: https://doi.org/10.21203/rs.3.rs-100834/v1

License: (c) (1) This work is licensed under a Creative Commons Attribution 4.0 International License. Read Full License

Version of Record: A version of this preprint was published at Respiratory Research on April 6th, 2021. See the published version at https://doi.org/10.1186/s12931-021-01675-2. 


\section{Abstract}

Background: Whole lung tissue transcriptomic profiling studies in chronic obstructive pulmonary disease (COPD) have led to the identification of several genes associated with the severity of airflow limitation and/or the presence of emphysema, however, the cell types driving these gene expression signatures remain unidentified.

Methods: To determine cell specific transcriptomic changes in severe COPD, we conducted single-cell RNA sequencing (scRNA seq) on $n=29,961$ cells from the peripheral lung parenchymal tissue of nonsmoking subjects without underlying lung disease $(\mathrm{n}=3)$ and patients with severe COPD $(\mathrm{n}=3)$. The cell type composition and cell specific gene expression signature was assessed. Gene set enrichment analysis (GSEA) was used to identify the specific cell types contributing to the previously reported transcriptomic signatures.

Results: T-distributed stochastic neighbor embedding and clustering of scRNA seq data revealed a total of 17 distinct populations. Among them, the populations with more differentially expressed genes in cases vs. controls (log fold change $>|0.4|$ and FDR=0.05) were: monocytes $(n=1499)$; macrophages $(n=868)$ and ciliated epithelial cells $(n=590)$, respectively. Using GSEA, we found that only ciliated and cytotoxic T cells manifested a trend towards enrichment of the previously reported 127 regional emphysema gene signatures (normalized enrichment score $[\mathrm{NES}]=1.28$ and $=1.33, \mathrm{FDR}=0.085$ and $=0.092$ respectively). Among the significantly altered genes present in ciliated epithelial cells of the COPD lungs, QKI and IGFBP5 protein levels were also found to be altered in the COPD lungs.

Conclusions: scRNA seq is useful to identify transcriptional changes and possibly individual protein levels that may contribute to the development of emphysema in a cell-type specific manner.

\section{Background}

Chronic obstructive pulmonary disease (COPD) is a common respiratory disorder characterized by irreversible expiratory airflow limitation in response to inhalation of noxious stimuli (e.g., cigarette smoke) [1]. COPD is the third leading cause of death [2] and a major economic burden in the United States [3].

COPD is a heterogeneous disorder that can manifest with multiple clinical phenotypes, including emphysema (destructive enlargement of the airspaces distal to terminal bronchioles), chronic bronchitis, and small airway disease [4-7]. Over the last few decades, several lung homogenates and airway transcriptomic studies have been conducted in order to reveal molecular pathways linked to the pathogenesis of smoking-related airflow limitations and emphysema [8-12]. These studies have resulted in the identification of several biological processes, now believed to be associated with smoking-related FEV1 decline [13-15], including 1) chronic immune response and inflammation [16, 17]; 2) imbalance of proteases/anti-proteases [18]; 3) oxidative stress [19, 20]; 4) cellular senescence (permanent loss of proliferative capacity) [21, 22]; and 5) lung epithelial cell (LEC) apoptosis. 
In one of the most comprehensive transcriptomic analyses of smoking-related emphysema to date, Campbell, et al. profiled gene expression in 8 separate regions from 6 emphysematous lungs, based on degree of emphysema, and compared transcriptome with 2 non-diseased lungs ( 8 regions $\times 8$ lungs $=64$ samples). They identified a total of 127 genes with expression levels significantly correlating with the emphysema severity [23]. Many genes upregulated with increased emphysema severity were involved in inflammation (e.g., the B-cell receptor signaling), while those downregulated with increasing disease severity were implicated in tissue repair (e.g., the transforming growth factor beta (TGF $\beta$ ) pathway) [23]. This 127 gene emphysema signature was enriched in the transversal studies of lung tissue of patients with severe COPD and emphysema $[13,15]$. However, it remains to be elucidated which specific cell types contribute most to this smoking-related emphysematous and small airflow damage transcriptome signature.

Here, we used scRNA-seq technology to identify lung cell-type specific gene expression signatures associated with airflow limitation and/or emphysema. We examined the single-cell transcriptomes of cell populations from lung tissue samples obtained from a representative selection of 3 ex-smokers with severe COPD/emphysema and 3 nonsmokers without any history of lung disease. We compared our findings with previously reported whole lung tissue homogenate airflow limitation and emphysema signatures, and experimentally validated the key associated genes.

\section{Methods}

\section{Human Lung Tissue Samples}

For scRNA seq, fresh lung parenchymal tissue samples were obtained from the upper lobes of three nonsmoking subjects without underlying lung disease who underwent warm autopsies and three patients with severe COPD who received lung transplantation (Table 1). For immunoblot analysis (Fig. 2A), frozen lung parenchymal tissue obtained from smokers without any history of lung disease $(n=5)$, or very severe $\operatorname{COPD}(n=7)$, both were provided by the University of Pittsburgh, Lung Tissue Research Consortium (LTRC), respectively (Table 5). Data from the Lung Genomics Research Consortium (LGRC) Cohort was used for gene expression analysis of QKI and IGFBP5 (Table 6). The COPD Specialized Center for Clinically Oriented Research (SCCOR) cohort was utilized for comparison of serum IGFBP5 levels between 40 patients with COPD and 40 smokers without clinically evident COPD (Table 7). 
Table 1

Three normal nonsmokers and three patients with severe COPD.

\begin{tabular}{|lllllll|}
\hline ID & Age & Sex & $\begin{array}{l}\text { Smoking } \\
\text { (Pack-years) }\end{array}$ & FEV1/FVC & FEV1\% ref. & DLCO \% ref. \\
\hline NL 1 & 57 & F & None & NA & NA & NA \\
\hline NL 2 & 18 & M & None & NA & NA & NA \\
\hline NL 3 & 23 & F & None & NA & NA & NA \\
\hline COPD 1 & 65 & F & 60 & 0.33 & 33 & 14 \\
\hline COPD 2 & 62 & F & 75 & 0.29 & 22 & 53 \\
\hline COPD 3 & 61 & F & 45 & 0.25 & 21 & 20 \\
\hline
\end{tabular}

Table 4

GSEA enrichment results of the different clusters with the differential gene expression of the LTRC (COPD Gold 4 vs. Non-smokers).

\begin{tabular}{|lllllll|}
\hline & SIZE & ES & NES & NOM p-value & FDR q-value & FWER p-value \\
\hline Mast cells & 70 & -0.62 & -1.72 & 0.00 & 0.07 & 0.04 \\
\hline Proliferating macrophages & 164 & -0.56 & -1.71 & 0.01 & 0.04 & 0.05 \\
\hline Monocytes & 103 & -0.63 & -1.58 & 0.03 & 0.10 & 0.12 \\
\hline FBPB4 macrophages & 27 & -0.61 & -1.46 & 0.04 & 0.15 & 0.23 \\
\hline AT2 & 80 & -0.56 & -1.56 & 0.06 & 0.09 & 0.14 \\
\hline B cells & 48 & -0.47 & -1.42 & 0.07 & 0.14 & 0.28 \\
\hline Club & 83 & -0.51 & -1.38 & 0.09 & 0.16 & 0.32 \\
\hline Fibroblasts & 245 & -0.49 & -1.45 & 0.12 & 0.13 & 0.24 \\
\hline Cytotoxic T cells & 30 & -0.54 & -1.33 & 0.13 & 0.16 & 0.39 \\
\hline Low quality T cells & 126 & -0.45 & -1.38 & 0.13 & 0.14 & 0.33 \\
\hline Ciliated & 55 & -0.48 & -1.17 & 0.30 & 0.30 & 0.57 \\
\hline T cells & 36 & -0.42 & -1.14 & 0.32 & 0.30 & 0.60 \\
\hline Endothelial & 94 & -0.36 & -0.93 & 0.53 & 0.51 & 0.76 \\
\hline AT1 & 221 & -0.12 & -0.56 & 0.97 & 0.99 & 0.92 \\
\hline NK cells & 23 & -0.21 & -0.55 & 0.97 & 0.93 & 0.92 \\
\hline
\end{tabular}


Table 5

Clinical and Demographics of the control and COPD subjects (Immunoblot Analysis)

\begin{tabular}{|lll|}
\hline & Control & COPD (GOLD Stage 4) \\
\hline Number of subjects & 5 & 7 \\
\hline Age, yr, mean (SD) & $62.0(10.0)$ & $62.0(2.8)$ \\
\hline Gender & $3 \mathrm{M} / 2 \mathrm{~F}$ & $4 \mathrm{M} / 3 \mathrm{~F}$ \\
\hline Smoking (pack-years) & $35(10.6)$ & $50.7(23.1)$ \\
\hline
\end{tabular}

Table 6

Clinical and Demographics of the Lung Genomics Research Consortium (LGRC) Cohort (used for QKI and IGFBP5 gene expression analysis)

\begin{tabular}{|lll|}
\hline & Control & COPD \\
\hline Number of subjects & 108 & 219 \\
\hline Age, yr, mean (SD) & $63.6(11.4)$ & $64.7(9.7)$ \\
\hline Gender (\% Female) & $55 \%$ & $43 \%$ \\
\hline Smoking status, (\%) & & \\
\hline Never & $30 \%$ & $5.50 \%$ \\
\hline Current & $1.90 \%$ & $6.40 \%$ \\
\hline Ever & $58 \%$ & $86.70 \%$ \\
\hline Unknown & $10.10 \%$ & $1.40 \%$ \\
\hline Pulmonary function, mean (SD) & & \\
\hline FEV1, \% Predicted & $95(12.6)$ & $50.6(24.0)$ \\
\hline FVC, \% Predicted & $94.4(13.1)$ & $73,8(19.5)$ \\
\hline DLCO, \% Predicted & $84.1(16.7)$ & $56.6(23.1)$ \\
\hline Emphysema, \% mean (SD) & & $15.4(17.1)$ \\
\hline DLCO = diffusing capacity of the lung for carbon monoxide \\
\hline
\end{tabular}


Clinical and Demographics of the SCCOR Cohort (used for IGFBP5 ELISA)

\begin{tabular}{|lll|}
\hline & Control & COPD \\
\hline Number of subjects & 40 & 40 \\
\hline Age, yr, mean (SD) & $66.7(7.5)$ & $67.5(6.4)$ \\
\hline Gender (\% Female) & $42.50 \%$ & $42.50 \%$ \\
\hline Current Smoking (\%) & $47.50 \%$ & $40 \%$ \\
\hline Pack Years (SD) & $50.3(30.5)$ & $65.4(29.1)$ \\
\hline Pulmonary function, mean (SD) & & $70.7 \pm 18.8 \%$ \\
\hline FEV1, \% Predicted & $99.1 \pm 14.7 \%$ & $0.535 \pm 0.104$ \\
\hline FEV1/FVC Ratio & $0.763 \pm 0.037$ & $0.107 \pm 0.086$ \\
\hline Emphysema \%F950* & $0.005 \pm 0.003$ & \\
\hline $\begin{array}{l}\text { * \% low-attenuation area defined as the fraction of voxels less than }-950 \text { Houndsfield Unit of total } \\
\text { voxels identified in regions of the lung. }\end{array}$ & \\
\hline
\end{tabular}

\section{Preparation of single-cell libraries, sequencing, and analysis}

The whole lung tissue samples were processed as described previously [24]. Briefly, lung tissue samples were digested, cell suspensions laded into the Chromium instrument (10X Genomics, Pleasanton, CA), and the resulting barcoded cDNAs were used to construct libraries. RNA-seq was conducted on all mixed samples as a pool. The total number of reads for the 3 single cell COPD samples was: $456,870,504$ reads. Cell-gene specific molecular identifier counting matrices were generated and analyzed using Seurat [25] to identify distinct cell populations [26] and hierarchically clustered using Cluster 3.0 [27].

\section{Reagents and Antibodies}

Chemicals were obtained from Sigma Chemical and Calbiochem. Polyvinylidene difluoride membranes were obtained from Bio-Rad. ECL Plus was obtained from Amersham. Antibodies were obtained from various sources: HPRT1 and EPAS1 antibodies were obtained from Cell Signaling; QKI, RTN4, STOM, IGFBP5 and secondary antibodies (horseradish peroxidase-conjugated anti-rabbit or anti-mouse Ig) were obtained from Santa Cruz Biotechnology.

\section{Immunoblot analysis}

Human lung tissues (control and severe COPD groups) were thawed and homogenized in RIPA buffer using a Bullet Blender (next advance). Samples were centrifuged at $4{ }^{\circ} \mathrm{C}$ for $10 \mathrm{~min}$ at $12000 \mathrm{G}$ and resuspended in protein loading buffer. For western blot, about 30 ug of proteins were separated by SDSPAGE gel and transferred into a nitrocellulose membrane. Membranes were blocked and incubated with 
primary antibodies and the appropriated secondary antibody HRP conjugated. The signal was acquired with Chemi-Doc MP (Bio-Rad) using WesternBright Sirius HRP substrate (advansta).

\section{ELISA for IGFBP5}

The IGFBP5 Human ELISA Kit was purchased from Thermal Fisher Scientific. Serum IGFBP5 levels were measured from 40 control smokers and 40 smokers with COPD according to the vendors instructions.

\section{Gene Ontology enrichment and GSEA}

Gene Set Enrichment Analysis (GSEA) was used to identify similarities with previously published emphysema and severity signatures [28]. The gene ontology biological process enrichment was done in $\mathrm{R}$ with the ClusterProfiler package [29], and the ontologies were summarized and visualized with the Revigo package [30].

\section{Results}

\section{Single cell RNA sequencing reveals 17 distinct cell clusters from human lungs with severe COPD.}

We conducted single cell transcriptomic analysis of all cells obtained from the whole parenchymal lung tissue of three nonsmokers without underlying lung disease and three patients with severe COPD (demographic data: Table 1). The pathology with the H\&E staining confirmed the presence of moderate to severe emphysematous changes in all three COPD patients (see Supplementary Figure S1). We examined a total of 29,961 cells from six subjects (3914-5920 cells/sample). All the samples were pooled and analyzed together to gain the power to detect rare cell types as described previously [24]. t-distributed stochastic neighbor embedding (t-SNE) blots were generated using statistically significant principal components and cells were clustered using an unbiased graph-based clustering algorithm (smart local moving [SLM] clustering), which in identified 17 distinct types of cells (Fig. 1A). Cells from disease conditions and the individual subjects were indicated in different colors (Figs. 1B and 1C, respectively). SLM clustering was made according to the distinct gene expression patterns based on various cell types in the lung (Fig. 1D). The cell clusters that cannot be reliably classified due to fewer unique molecular identifiers were referred as "low quality" cells. Cell clusters were predominantly identified as: FABP4 as a cell cluster of FABP4 macrophages (\#0); S100A8 as a cluster of monocytes (\#1); CD3D as cytotoxic T cells (\#2); GNLY as NK cells (\#3); CLDN5 as endothelial cells (\#4); LTB as T cells (\#5); IGKC as B cells (\#6); CAPS as ciliated epithelial cells (\#7); SFTPC as alveolar type 2 epithelial (AT2) cells (\#8); MALAT1 as low quality T cells (\#9); RSPH1 as low quality cells (\#10); DCN as fibroblasts (\#11); SCGB1A1 as club epithelial cells (\#12); AGER as alveolar type 1 epithelial (AT1) cells (\#13); CCL21 as lymphatic endothelial cells (\#14); TPSAB1 as mast cells (\#15); KIAA0101 as proliferating macrophages (\#16). These and other markers provided strong transcriptome signatures for each cell cluster (see Supplementary Table 1, shown graphically in feature plots (Fig. 1E). The prevalence of individual cell types between normal nonsmokers and patients with COPD is shown in Table 2. None of the difference in the abundance of individual cell types between normal nonsmokers and COPD patients reached statistical significance (Wilcoxon), however, a trend existed for decreased percentages of macrophages, endothelial cells, AT2 cells, and fibroblasts in the COPD lungs. 
Page $9 / 23$ 
Table 2

Identified clusters, number of differentially expressed genes in Case vs. control, mean \% of cells belonging to this cluster both in cases and controls, fold change differences between cluster percentage and the $p$ value of the comparison of the cluster frequency in cases vs. controls both with t-test and Wilcoxon-test.

\begin{tabular}{|c|c|c|c|c|c|c|c|c|c|}
\hline Cluster & Population & $\begin{array}{l}\text { \# DE } \\
\text { genes }\end{array}$ & up & down & $\begin{array}{l}\text { Control } \\
\% \text { of } \\
\text { cells }\end{array}$ & $\begin{array}{l}\text { COPD } \\
\% \text { of } \\
\text { cells }\end{array}$ & $\begin{array}{l}\text { Fold } \\
\text { Change }\end{array}$ & $\begin{array}{l}P \\
\text { value } \\
\text { (t.test) }\end{array}$ & $\begin{array}{l}\text { P value } \\
\text { (Wilcox) }\end{array}$ \\
\hline 0 & $\begin{array}{l}\text { FABP4 } \\
\text { Macrophages }\end{array}$ & 868 & 620 & 248 & $\begin{array}{l}27.97 \\
\pm \\
10.74\end{array}$ & $\begin{array}{l}5.15 \\
\pm 1.57\end{array}$ & 5.43 & 0.02 & 0.057 \\
\hline 1 & Monocytes & 1499 & 677 & 822 & $\begin{array}{l}23.80 \\
\pm \\
12.90\end{array}$ & $\begin{array}{l}11.24 \\
\pm 4.84\end{array}$ & 2.12 & 0.18 & 0.23 \\
\hline 2 & $\begin{array}{l}\text { Cytotoxic T } \\
\text { cells }\end{array}$ & 539 & 165 & 374 & $\begin{array}{l}11.18 \\
\pm 6.48\end{array}$ & $\begin{array}{l}21.86 \\
\pm 9.80\end{array}$ & -1.96 & 0.14 & 0.11 \\
\hline 3 & NK cells & 431 & 233 & 198 & $\begin{array}{l}3.85 \pm \\
2.89\end{array}$ & $\begin{array}{l}22.14 \\
\pm \\
27.41\end{array}$ & -5.75 & 0.23 & 0.4 \\
\hline 4 & Endothelial & 242 & 185 & 57 & $\begin{array}{l}9.17 \pm \\
3.90\end{array}$ & $\begin{array}{l}2.37 \\
\pm 0.52\end{array}$ & 3.87 & 0.03 & 0.057 \\
\hline 5 & T cells & 213 & 64 & 149 & $\begin{array}{l}2.11 \pm \\
1.00\end{array}$ & $\begin{array}{l}11.68 \\
\pm 9.02\end{array}$ & -5.54 & 0.08 & 0.23 \\
\hline 6 & B Cells & 153 & 30 & 123 & $\begin{array}{l}0.99 \pm \\
0.59\end{array}$ & $\begin{array}{l}6.80 \\
\pm 7.95\end{array}$ & -6.84 & 0.19 & 0.23 \\
\hline 7 & Ciliated & 590 & 433 & 157 & $\begin{array}{l}1.84 \pm \\
0.98\end{array}$ & $\begin{array}{l}6.18 \\
\pm 4.36\end{array}$ & -3.35 & 0.10 & 0.23 \\
\hline 8 & AT2 & 476 & 34 & 442 & $\begin{array}{l}4.12 \pm \\
2.52\end{array}$ & $\begin{array}{l}0.96 \\
\pm 0.32\end{array}$ & -4.28 & 0.09 & 0.057 \\
\hline 9 & $\begin{array}{l}\text { Low quality } T \\
\text { cells }\end{array}$ & 41 & 14 & 27 & $\begin{array}{l}1.75 \pm \\
0.68\end{array}$ & $\begin{array}{l}3.71 \\
\pm 2.07\end{array}$ & -2.12 & 0.13 & 0.11 \\
\hline 10 & $\begin{array}{l}\text { Low quality } \\
\text { cells }\end{array}$ & 596 & 369 & 227 & $\begin{array}{l}2.02 \pm \\
0.95\end{array}$ & $\begin{array}{l}2.83 \\
\pm 1.50\end{array}$ & -1.40 & 0.41 & 0.63 \\
\hline 11 & Fibroblasts & 96 & 87 & 9 & $\begin{array}{l}3.17 \pm \\
1.62\end{array}$ & $\begin{array}{l}0.27 \\
\pm 0.07\end{array}$ & 11.60 & 0.03 & 0.057 \\
\hline 12 & Club cells & 98 & 70 & 28 & $\begin{array}{l}1.35 \pm \\
0.81\end{array}$ & $\begin{array}{l}2.72 \\
\pm 2.16\end{array}$ & -2.02 & 0.29 & 0.63 \\
\hline 13 & AT1 & 68 & 59 & 9 & $\begin{array}{l}2.60 \pm \\
1.91\end{array}$ & $\begin{array}{l}0.46 \\
\pm 0.36\end{array}$ & 5.71 & 0.12 & 0.11 \\
\hline 14 & $\begin{array}{l}\text { Lymphatic- } \\
\text { endothelial }\end{array}$ & 27 & 20 & 7 & $\begin{array}{l}1.93 \pm \\
1.10\end{array}$ & $\begin{array}{l}0.33 \\
\pm 0.29\end{array}$ & 5.85 & 0.06 & 0.23 \\
\hline 15 & Mast cells & 32 & 25 & 7 & $\begin{array}{l}1.32 \pm \\
0.79\end{array}$ & $\begin{array}{l}0.91 \\
\pm 0.24\end{array}$ & 1.44 & 0.44 & 0.63 \\
\hline
\end{tabular}




\begin{tabular}{|llllllllll|}
\hline Cluster & Population & $\begin{array}{l}\text { \# DE } \\
\text { genes }\end{array}$ & up & down & $\begin{array}{l}\text { Control } \\
\text { \% of } \\
\text { cells }\end{array}$ & $\begin{array}{l}\text { COPD } \\
\% \text { of } \\
\text { cells }\end{array}$ & $\begin{array}{l}\text { Fold } \\
\text { Change }\end{array}$ & $\begin{array}{l}\text { P } \\
\text { value } \\
\text { (t.test) }\end{array}$ & $\begin{array}{l}\text { P value } \\
\text { (Wilcox) }\end{array}$ \\
\hline 16 & $\begin{array}{l}\text { Proliferative } \\
\text { macrophages }\end{array}$ & 111 & 55 & 56 & $\begin{array}{l}0.84 \pm \\
0.35\end{array}$ & $\begin{array}{l}0.39 \\
\pm 0.25\end{array}$ & 2.17 & 0.12 & 0.11 \\
\hline
\end{tabular}

\section{Gene expression in 17 individual types of cells in severe emphysematous lungs.}

For each cluster, the differential gene expression among the cells of the 3 COPD patients vs. the controls was computed using a Wilcoxon test. This analysis identified the number of differentially expressed genes per cluster when applying the filter of log fold change $>|0.4|$ and FDR $=0.05$ (Supplementary Table S2). Interestingly, the major populations showing the largest differences in gene expression were: monocytes, macrophages, low quality cells, ciliated epithelial cells, T cells, AT2 cells, and NK cells (Table 2). Most gene expression changes corresponded to an increased transcription (up-regulation) in patients with COPD (Table 2).

\section{The Gene Ontology enrichment Gene expression in 17 individual types of cells from severe emphysematous lungs.}

Next, we performed the functional enrichment with the upregulated or downregulated genes in COPD for each population for GO biological processes (Supplementary Tables 3 and 4). Results for the upregulated genes in COPD (i.e., macrophages, monocytes, ciliated epithelial cells and NK cells), have been summarized with Revigo and are shown as Treemaps (Supplementary Figures S2-S5). Of note, these four individual cell types shared ontologies related to the activation of T cells, defense response and three of them (not macrophages) also presented ontologies related to the viral life cycle.

\section{Single cell contribution to the 127 emphysema-related gene signatures}

Next, we identified how the transcriptomic changes of each cell type contribute to the previously described 127 gene signatures of emphysema reported by Campbell et al [23]. We computed the overlap using GSEA (Table 3). Three individual cell types were enriched with a nominal $p$ value $<0.05$ and an FDR $<0.1$ (i.e., ciliated epithelial cells, cytotoxic T cells, and low quality T cells). The genes in the core enrichment for these 3 individual cell types and the values of differentially expressed genes in Campbell's data set are shown in Supplementary Table 5. EPAS1, QKI and STOM were differentially expressed core genes in all three-cell types (Supplementary Table 5). 
Table 3

GSEA enrichment of the different clusters with the 127 gene signature

\begin{tabular}{|llllll|}
\hline Cluster & ES & NES & NOM $p$-val & FDR q-val & FWER $p$-val \\
\hline Ciliated & 0.33 & 1.33 & 0.00 & 0.09 & 0.00 \\
\hline Cytotoxic T & 0.33 & 1.29 & 0.00 & 0.09 & 0.00 \\
\hline Low quality & 0.47 & 1.29 & 0.00 & 0.11 & 0.00 \\
T cells & & & & & \\
\hline AT2 & 0.39 & 1.27 & 0.09 & 0.18 & 0.04 \\
\hline Fibroblasts & 0.40 & 1.31 & 0.10 & 0.18 & 0.05 \\
\hline T cells & 0.31 & 1.17 & 0.10 & 0.21 & 0.05 \\
\hline Proliferative macrophages & 0.37 & 1.23 & 0.10 & 0.22 & 0.05 \\
\hline B cells & -0.24 & -0.97 & 0.18 & 0.28 & 0.09 \\
\hline NK & 0.31 & 1.05 & 0.29 & 0.37 & 0.14 \\
\hline AT1 & 0.33 & 1.00 & 0.43 & 0.52 & 0.22 \\
\hline Monocytes & 0.20 & 0.84 & 0.68 & 0.77 & 0.36 \\
\hline Macrophages & -0.22 & -0.92 & 0.70 & 0.83 & 0.37 \\
\hline Club & -0.20 & -0.82 & 0.76 & 0.88 & 0.39 \\
\hline Low quality & -0.25 & -0.78 & 0.88 & 1.00 & 0.43 \\
\hline Endothelial & -0.17 & -0.53 & 0.89 & 1.00 & 0.44 \\
\hline Mast cells & 0.28 & 0.77 & 0.92 & 1.00 & 0.47 \\
\hline
\end{tabular}

As a complementary analysis, we showed which individual cell types differentially expressed the 127 emphysema related genes (Supplementary Table 6 and Supplementary Fig. 6). FCN3, RTN4 and CCR7 were differentially expressed in a total of 5 individual cell types, and EPAS1, QKI and STOM in the 4 individual cell types. The individual cell types with more differentially expressed genes were: monocytes $(n=10)$, AT2 cells $(n=9)$, macrophages $(n=8)$, ciliated cells $(n=5)$, and T cells $(n=5)$.

\section{Comparison with severe airflow limitation genes.}

Next, we determined whether the gene expression changes observed in the individual cell types represent the previously identified gene signatures in whole lung tissue of patients with severe airflow limitation. To achieve this, we assessed the enrichment with GSEA of the individual cell types with the differentially expressed genes between $n=17$ non-smokers and $n=30$ patients with GOLD stage 4 obtained from LTRC (GSE47460, GPL14550). Overall, the enrichment in all individual cell types appeared to be consistent with 
the genes differentially expressed in whole lung tissue. However, the enrichment was significant at a nominal $p$ value for only 4 individual cell types (mast cells, proliferating macrophages, monocytes, and FBPB4 macrophages). The full list of genes differentially expressed in the LTRC and differentially expressed in the individual cell clusters is shown in Supplementary Table 7.

Our analysis identified several genes expressed in a distinct type of cells, which were previously reported to be differentially expressed in lung tissue homogenates according to the severity of airflow limitation $[14,31]$. These genes are FGG (AT2 cells), CCL19 (monocytes), PLA2G7 (macrophages), HP (macrophages), TNFSF13B (monocytes) and FCRLA (B cells). In addition, following genes were differentially expressed in several individual types of cells: S100A10 $(n=7)$, RPS10, GNG11, and CAV1 ( $n=$ $6)$, S100A6 $(n=5)$, and AGER $(n=4)$.

\section{Quantifying protein levels of some genes significantly altered between normal and COPD lungs.}

To determine whether significantly altered genes between normal and COPD lungs also correlate with the related protein levels, whole parenchymal lung tissues from non-smokers without COPD ( $n=5$ per group) and former-smokers with COPD GOLD stage 3 or 4 ( $n=6$ or 7 per group) were evaluated for protein expression of QKI, STOM, EPAS1, and IGFBP5 by immunoblot analysis. Consistent with altered gene expression, QKI and IGFBP5 protein levels were significantly increased in the COPD lungs relative to nonsmokers (Figs. 2A and 2B), but neither STOM nor EPAS1 protein levels were altered (Supplementary Figure S7A). Further, we determined whether QKI and IGFBP5 gene expressions in whole lung tissue correlated with the emphysema severity. QKI expression appreared to decrease according to \% emphysema $(n=208$; $p=0.0854)$, whereas, IGFBP5 expression significantly increased according to $\%$ emphysema $(p=00150)$. Since IGFBP5 is an excretory protein, we measured the serum levels of IGFBP5 in smokers with or without COPD ( $n=40$, each group) that were not significantly altered between the two group (Supplementary

Figure S7B). These results suggest that some of the significantly altered genes in COPD lungs identified by scRNA seq indeed correlate with the individual protein levels in the whole lung tissue.

\section{Discussion}

This study uses scRNA seq from human lung homogenate in order to identify the specific cell types driving gene expression changes found in bulk RNA sequencing of patients with severe emphysema and airway obstruction. We found that: 1) t-SNE and clustering of scRNA-seq data identified a total of 17 distinct populations based on predetermined markers per cell type. Monocytes, macrophages, ciliated cells and low quality cells exhibited more differentially expressed genes in cases vs. controls relative to the other cell types; 2) GSEA revealed that the populations contributing most to the previously reported emphysema signature were ciliated cells, cytotoxic $T$ cells and low quality $T$ cells. While in the severe COPD LTRC signature, the populations enriched by GSEA were proliferating macrophages, mast cells, AT2 cells and monocytes; 3 ) key COPD associated genes were found to be expressed by specific cell types:. FGG (AT2 cells), CCL19/TNFSF13B (Monocytes) and PLA2G7 (Macrophages); 4) We verified the expression of some of the specific scRNA seq differentially expressed genes at protein level as well (i.e. QKI and IGFBP5). 


\section{Previous studies}

Although the scRNA seq methodology has been applied to the profiling of lung tissue of patients with IPF [32-34], this is the first study to our knowledge which profiles lung tissue of patients with COPD. In relation to severe COPD and emphysema, several studies have reported the transcriptomic profile of lung tissue homogenates $[14,31]$, but the scRNA seq has several advantages over the previously used RNA seq methods. First, scRNA seq is useful to determine specific types of cells that are responsible for the significant transcriptomic changes in a disease process (e.g., the emphysematous and/or airflow limitation signature). Second, it is unlikely that the cell composition alters the outcome such as the whole cell RNA-sEq. Third, scRNA seq may uncover an important molecular pathway unique to a specific cell type that contributes to the development of the disease.

\section{Interpretation of novel findings}

We identified 17 cell subtypes in lung tissue of patients with severe COPD and non-smoking controls. In relation to cell composition, differences were not statistically significant, but in agreement with previous reports. We observed an overall increase of immune cell types (T, NK and B cells) and decrease of structural cells (Fibroblasts, AT2 cells and endothelial cells) [35]. However, sampling effects inherent to scRNA seq may have contributed to the skewed proportion of distinct cell populations. Interestingly, we found that the genes up-regulated in the cell types with more differential expression (Monocytes, Macrophages, Ciliated cells, Cytotoxic T cells and AT2 cells) were related to T cell activation, antigen presentation and signaling. The role of Cytotoxic T cells (CD8+) in severe COPD has been long recognized [35-37] and emphysema has been proposed to be associated with a Th1 response activated by infiltrating ILC1, NK, and LTi cells [38]. Here, we expand these findings by showing that the antigen presenting cells (macrophages, monocytes and AT2 cells) are also involved in the T cell activation. Interestingly, the viral related ontologies appeared to be enriched in these cell types as well as in ciliated epithelial cells and NK cells. Further work profiling the virome in parallel with cellular phenotyping may complement these findings.

In relation to the previously described 127 emphysema gene signature, our GSEA analysis showed an enrichment of genes differentially expressed by Ciliated and T cells (Cytotoxic and of low quality), suggesting an active involvement of $T$ cells in the emphysematous tissue remodeling and accumulation of primary cilia [38,39]. Some of the genes associated with the homing of B cells and previously identified by homogenate tissue profiling (i.e. CCL19, TNFSF13B) $[23,31]$ were found in the current study to be expressed by macrophages and monocytes. Yet in the current analysis the increase in $B$ cells was observed in 2 of the 3 severe COPD samples, and the genes hyper expressed by the severe COPD B cells were related to the $T$ cell activation in concordance with previous works [31]. Upregulation of gene expression for fibrinogen (FGG) is a well-recognized biomarker in COPD [40] and is produced by AT2 cells. Fibrinogen has a well-known role in both innate and $T$ cell mediated adaptive immune responses to bacteria [41]. Similar to these previous findings, our analysis showed an upregulation of genes related to the antigen presentation in AT2 cells, suggesting a role in the stimulation and perpetuation of the observed immune response in the lung. AGER, another well-known gene associated with COPD [42], was 
upregulated in 4 cell types in our analysis (Macrophages, Monocytes, low quality T cells and B cells) that are associated with of immune response, suggesting a role of the RAGE axis in the chronic immune infiltrate observed in severe COPD/emphysema. In our analysis, club cells that express the COPD associated CC- 16 protein, were found to be altered in the mRNA catabolism pathways, and the response to toxic substances. Further investigation is warranted to determine the impact of these alterations in cell functionality [43].

Finally, in this study, we attempted to verify whether differences in gene expression correlated with differential protein content in the cellular populations derived from COPD and normal lungs. Among several common targets, we found that COPD lungs exhibit decreased protein levels of QKI and increased protein levels of IGFBP5.

Our scRNA seq data show that QKI is expressed abundantly in myeloid cells, endothelial cells, and AT1 cells, whereas IGFBP5 is expressed in ciliated cells, fibroblasts, and lymphatic endothelial cells relative to the other types of cells. QKI, a KH domain containing RNA binding protein, regulates versatile mRNA metabolism - splicing, export, stability, and protein translation [44]. The loss-of-function mutations disturb myelination and cause embryonic lethality [45]. QKI has been implicated in various disease processes, including atherosclerosis [46], tumorigenesis [47], and fibrosis [48]. IGFBP5, insulin-like growth factor binding protein 5, is one of the six proteins of the IGFBP family [49]. IGFBP proteins bind IGF-I/II and regulate their bioavailability and downstream signaling. In addition, IGFBP proteins can regulate cell growth and survival independent of IGF-I/II [49]. In particular, IGFBP5 plays a causal role in the induction of cellular senescence and inflammation [50], which may be linked to pulmonary fibrosis [51]. Further, an intergenic SNP of IGFBP5 (rs6435952) associates with airway obstruction [52]. Although IGFBP5 is a secretory protein [53], there was no significant change in the serum levels of IGFBP5 in COPD patients compared with control smokers. However, there may be excretory impairment of IGFBP5 protein in the COPD lung which remains to be determined in future studies. An in vivo animal study will be necessary to elucidate a causal role of QKI and IGFBP5 in the development of smoking-induced COPD.

\section{Limitations}

The main limitation of this study is the sample size as we have analyzed 4,000 to 6,000 cells/sample single cells pooled together from 3 control subjects without underlying lung disease and 3 patients with severe COPD. Accordingly, our findings are not representative of the COPD heterogeneity and we will need to increase the sample size to address this open issue in future investigations. Notwithstanding this limitation, the main focus of this work has been to use the generated data to explore which cell types express the key genes previously shown to be associated with COPD and emphysema.

\section{Conclusions}

We identified ciliated and CD8 + T cells as prominent cell types associated with the 127 gene signature associated with emphysema. Our findings support a prominent role of the immune response in severe COPD, with the implication of structural and antigen presenting cells in its homing and perpetuation. Finally, QKI and IGFBP5 are identified as potential COPD biomarkers, whose both gene and protein 
expression are significantly altered in COPD lungs relative to normal lungs. The causal role of QKI and IGFBP5 in the development of COPD/emphysema will need further investigation.

\section{List Of Abbreviations}

COPD, chronic obstructive pulmonary disease

CS, cigarette smoke

FDR, false discovery rate

SEGA, gene set enrichment analysis

ROS, reactive oxygen species

\section{Declarations}

\section{Ethics approval and consent to participate}

All research involving human subjects was approved by the University of Pittsburgh institutional review board (\#14010265 and 19090239). Written informed consent was obtained from all study subjects. The use of human cadaveric tissue and decedent medical records for this study was approved by the Committee for Oversight of Research and Clinical Training Involving Decedents (CORID) (\#765). The written consent was obtained either via body donation registration, autopsy authorization, or provided by next of kin or legal representatives.

\section{Consent for publication}

Not applicable.

\section{Availability of data and material}

All data generated or analyzed during this study are included in this published article [and its supplementary information files].

\section{Competing interests}

The authors declare that they have no completing interests.

\section{Funding}

This study was supported by the Merit Review Award from the US Department of Veterans Affairs (CX001048 and CX000105), AHA transformational grant to TN (19TPA34830061) and Miguel Servet Fellowship from the Instituto de Salud Carlos III (CP16/00039, PI17/00369) to RF. These founders had no role in study design, data collection and analysis, or preparation of the manuscript. 
Authors' contributions

All authors have read and approved the manuscript. MR, RL, RF, and TN conceived and designed the experiments; TS, XL, RV, PS, GN, JS, YZ performed the experiments; TS, XL, TK, GN, and RF collected and analyzed the data; $C Z, P S, Y Z, F S, M R$, JM, and TN provided reagents/materials/data analysis; $X L, T S, C Z$, $P S, M R, P S, D C, R M, F S$ edited the manuscript; $X L, G N$, RF, and TN wrote the paper.

\section{Acknowledgements}

Not applicable.

\section{References}

1. Brown DW: Smoking prevalence among US veterans. J Gen Intern Med 2010, 25(2):147-149.

2. Han MK: Update in chronic obstructive pulmonary disease in 2010. Am J Respir Crit Care Med 2011, 183(10):1311-1315.

3. Guarascio AJ, Ray SM, Finch CK, Self TH: The clinical and economic burden of chronic obstructive pulmonary disease in the USA. Clinicoecon Outcomes Res 2013, 5:235-245.

4. Hogg JC: Pathophysiology of airflow limitation in chronic obstructive pulmonary disease. Lancet 2004, 364(9435):709-721.

5. Kim V, Criner GJ: Chronic bronchitis and chronic obstructive pulmonary disease. Am J Respir Crit Care Med 2013, 187(3):228-237.

6. Martinez FJ, Foster G, Curtis JL, Criner G, Weinmann G, Fishman A, DeCamp MM, Benditt J, Sciurba F, Make $B$ et al: Predictors of mortality in patients with emphysema and severe airflow obstruction. $A m \mathrm{~J}$ Respir Crit Care Med 2006, 173(12):1326-1334.

7. Minai OA, Benditt J, Martinez FJ: Natural history of emphysema. Proc Am Thorac Soc 2008, 5(4):468474.

8. Morrow JD, Chase RP, Parker MM, Glass K, Seo M, Divo M, Owen CA, Castaldi P, DeMeo DL, Silverman EK et al: RNA-sequencing across three matched tissues reveals shared and tissue-specific gene expression and pathway signatures of COPD. Respir Res 2019, 20(1):65.

9. Faner R, Morrow JD, Casas-Recasens S, Cloonan SM, Noell G, Lopez-Giraldo A, Tal-Singer R, Miller BE, Silverman EK, Agusti A et al: Do sputum or circulating blood samples reflect the pulmonary transcriptomic differences of COPD patients? A multi-tissue transcriptomic network META-analysis. Respir Res 2019, 20(1):5.

10. Spira A, Beane J, Pinto-Plata V, Kadar A, Liu G, Shah V, Celli B, Brody JS: Gene expression profiling of human lung tissue from smokers with severe emphysema. Am J Respir Cell Mol Biol 2004, 31(6):601610.

11. Lamontagne M, Timens W, Hao K, Bosse Y, Laviolette M, Steiling K, Campbell JD, Couture C, Conti M, Sherwood $\mathrm{K}$ et al: Genetic regulation of gene expression in the lung identifies CST3 and CD22 as potential causal genes for airflow obstruction. Thorax 2014, 69(11):997-1004. 
12. Kusko RL, Brothers li JF, Tedrow J, Pandit K, Huleihel L, Perdomo C, Liu G, Juan-Guardela B, Kass D, Zhang $S$ et al: Integrated Genomics Reveals Convergent Transcriptomic Networks Underlying COPD and IPF. Am J Respir Crit Care Med 2016.

13. Faner R, Cruz T, Casserras T, Lopez-Giraldo A, Noell G, Coca I, Tal-Singer R, Miller B, Rodriguez-Roisin R, Spira A et al: Network Analysis of Lung Transcriptomics Reveals a Distinct B Cell Signature in Emphysema. Am J Respir Crit Care Med 2016.

14. Morrow JD, Zhou X, Lao T, Jiang Z, DeMeo DL, Cho MH, Qiu W, Cloonan S, Pinto-Plata V, Celli B et al: Functional interactors of three genome-wide association study genes are differentially expressed in severe chronic obstructive pulmonary disease lung tissue. Sci Rep 2017, 7:44232.

15. Obeidat M, Nie Y, Fishbane N, Li X, Bosse Y, Joubert P, Nickle DC, Hao K, Postma DS, Timens W et al: Integrative Genomics of Emphysema Associated Genes Reveals Potential Disease Biomarkers. Am J Respir Cell Mol Biol 2017.

16. Barnes PJ, Shapiro SD, Pauwels RA: Chronic obstructive pulmonary disease: molecular and cellular mechanisms. Eur Respir J 2003, 22(4):672-688.

17. Barnes PJ: Inflammatory mechanisms in patients with chronic obstructive pulmonary disease. $J$ Allergy Clin Immunol 2016, 138(1):16-27.

18. Stockley RA: Neutrophils and protease/antiprotease imbalance. Am J Respir Crit Care Med 1999, 160(5 Pt 2):S49-52.

19. Rangasamy T, Cho CY, Thimmulappa RK, Zhen L, Srisuma SS, Kensler TW, Yamamoto M, Petrache I, Tuder RM, Biswal S: Genetic ablation of Nrf2 enhances susceptibility to cigarette smoke-induced emphysema in mice. J Clin Invest 2004, 114(9):1248-1259.

20. Sundar IK, Yao H, Rahman I: Oxidative stress and chromatin remodeling in chronic obstructive pulmonary disease and smoking-related diseases. Antioxid Redox Signal2013, 18(15):1956-1971.

21. Ito K, Barnes PJ: COPD as a disease of accelerated lung aging. Chest 2009, 135(1):173-180.

22. Ahmad T, Sundar IK, Lerner CA, Gerloff J, Tormos AM, Yao H, Rahman I: Impaired mitophagy leads to cigarette smoke stress-induced cellular senescence: implications for chronic obstructive pulmonary disease. FASEB J 2015, 29(7):2912-2929.

23. Campbell JD, McDonough JE, Zeskind JE, Hackett TL, Pechkovsky DV, Brandsma CA, Suzuki M, Gosselink JV, Liu G, Alekseyev YO et al: A gene expression signature of emphysema-related lung destruction and its reversal by the tripeptide GHK. Genome Med 2012, 4(8):67.

24. Tabib T, Morse C, Wang T, Chen W, Lafyatis R: SFRP2/DPP4 and FM01/LSP1 Define Major Fibroblast Populations in Human Skin. J Invest Dermatol 2018, 138(4):802-810.

25. Satija R, Farrell JA, Gennert D, Schier AF, Regev A: Spatial reconstruction of single-cell gene expression data. Nat Biotechnol 2015, 33(5):495-502.

26. Macosko EZ, Basu A, Satija R, Nemesh J, Shekhar K, Goldman M, Tirosh I, Bialas AR, Kamitaki N, Martersteck EM et al: Highly Parallel Genome-wide Expression Profiling of Individual Cells Using Nanoliter Droplets. Cell 2015, 161(5):1202-1214. 
27. de Hoon MJ, Imoto S, Nolan J, Miyano S: Open source clustering software. Bioinformatics 2004, 20(9):1453-1454.

28. Subramanian A, Tamayo P, Mootha VK, Mukherjee S, Ebert BL, Gillette MA, Paulovich A, Pomeroy SL, Golub TR, Lander ES et al: Gene set enrichment analysis: a knowledge-based approach for interpreting genome-wide expression profiles. Proc Natl Acad Sci U S A 2005, 102(43):15545-15550.

29. Yu G, Wang LG, Han Y, He QY: clusterProfiler: an R package for comparing biological themes among gene clusters. OMICS 2012, 16(5):284-287.

30. Supek F, Bosnjak M, Skunca N, Smuc T: REVIGO summarizes and visualizes long lists of gene ontology terms. PLoS One 2011, 6(7):e21800.

31. Faner R, Cruz T, Casserras T, Lopez-Giraldo A, Noell G, Coca I, Tal-Singer R, Miller B, Rodriguez-Roisin R, Spira A et al: Network Analysis of Lung Transcriptomics Reveals a Distinct B-Cell Signature in Emphysema. Am J Respir Crit Care Med 2016, 193(11):1242-1253.

32. Reyfman PA, Walter JM, Joshi N, Anekalla KR, McQuattie-Pimentel AC, Chiu S, Fernandez R, Akbarpour M, Chen Cl, Ren Z et al: Single-Cell Transcriptomic Analysis of Human Lung Provides Insights into the Pathobiology of Pulmonary Fibrosis. Am J Respir Crit Care Med 2019, 199(12):15171536.

33. Xu Y, Mizuno T, Sridharan A, Du Y, Guo M, Tang J, Wikenheiser-Brokamp KA, Perl AT, Funari VA, Gokey $\mathrm{JJ}$ et al: Single-cell RNA sequencing identifies diverse roles of epithelial cells in idiopathic pulmonary fibrosis. JCl Insight 2016, 1(20):e90558.

34. Morse C, Tabib T, Sembrat J, Buschur KL, Bittar HT, Valenzi E, Jiang Y, Kass DJ, Gibson K, Chen W et al: Proliferating SPP1/MERTK-expressing macrophages in idiopathic pulmonary fibrosis. Eur Respir $J$ 2019, 54(2).

35. Hogg JC, Chu F, Utokaparch S, Woods R, Elliott WM, Buzatu L, Cherniack RM, Rogers RM, Sciurba FC, Coxson $\mathrm{HO}$ et al: The nature of small-airway obstruction in chronic obstructive pulmonary disease. $\mathrm{N}$ Engl J Med 2004, 350(26):2645-2653.

36. Saetta M, Di Stefano A, Turato G, Facchini FM, Corbino L, Mapp CE, Maestrelli P, Ciaccia A, Fabbri LM: CD8+ T-lymphocytes in peripheral airways of smokers with chronic obstructive pulmonary disease. Am J Respir Crit Care Med 1998, 157(3 Pt 1):822-826.

37. Agusti A, Hogg JC: Update on the Pathogenesis of Chronic Obstructive Pulmonary Disease. N Eng/ J Med 2019, 381(13):1248-1256.

38. Suzuki M, Sze MA, Campbell JD, Brothers JF, 2nd, Lenburg ME, McDonough JE, Elliott WM, Cooper JD, Spira A, Hogg JC: The cellular and molecular determinants of emphysematous destruction in COPD. Sci Rep 2017, 7(1):9562.

39. Perotin JM, Coraux C, Lagonotte E, Birembaut P, Delepine G, Polette M, Deslee G, Dormoy V: Alteration of primary cilia in COPD. Eur Respir J 2018, 52(1).

40. Duvoix A, Dickens J, Haq I, Mannino D, Miller B, Tal-Singer R, Lomas DA: Blood fibrinogen as a biomarker of chronic obstructive pulmonary disease. Thorax 2013, 68(7):670-676. 
41. Sun $\mathrm{H}$ : The interaction between pathogens and the host coagulation system. Physiology (Bethesda) 2006, 21:281-288.

42. Cheng DT, Kim DK, Cockayne DA, Belousov A, Bitter H, Cho MH, Duvoix A, Edwards LD, Lomas DA, Miller BE et al: Systemic soluble receptor for advanced glycation endproducts is a biomarker of emphysema and associated with AGER genetic variants in patients with chronic obstructive pulmonary disease. Am J Respir Crit Care Med 2013, 188(8):948-957.

43. Laucho-Contreras ME, Polverino F, Gupta K, Taylor KL, Kelly E, Pinto-Plata V, Divo M, Ashfaq N, Petersen H, Stripp B et al: Protective role for club cell secretory protein-16 (CC16) in the development of COPD. Eur Respir J 2015, 45(6):1544-1556.

44. Vernet $\mathrm{C}$, Artzt $\mathrm{K}$ : STAR, a gene family involved in signal transduction and activation of RNA. Trends Genet 1997, 13(12):479-484.

45. Ebersole TA, Chen Q, Justice MJ, Artzt K: The quaking gene product necessary in embryogenesis and myelination combines features of RNA binding and signal transduction proteins. Nat Genet 1996, 12(3):260-265.

46. de Bruin RG, Shiue L, Prins J, de Boer HC, Singh A, Fagg WS, van Gils JM, Duijs JM, Katzman S, Kraaijeveld $\mathrm{AO}$ et al: Quaking promotes monocyte differentiation into pro-atherogenic macrophages by controlling pre-mRNA splicing and gene expression. Nat Commun 2016, 7:10846.

47. Mukohyama J, Isobe T, Hu Q, Hayashi T, Watanabe T, Maeda M, Yanagi H, Qian X, Yamashita K, Minami $\mathrm{H}$ et al: miR-221 targets QKI to enhance the tumorigenic capacity of human colorectal cancer stem cells. Cancer Res 2019.

48. Chothani S, Schafer S, Adami E, Viswanathan S, Widjaja AA, Langley SR, Tan J, Wang M, Quaife NM, Jian Pua C et al: Widespread Translational Control of Fibrosis in the Human Heart by RNA-Binding Proteins. Circulation 2019, 140(11):937-951.

49. Baxter RC: IGF binding proteins in cancer: mechanistic and clinical insights. Nat Rev Cancer 2014, 14(5):329-341.

50. Sanada F, Taniyama Y, Muratsu J, Otsu R, Shimizu H, Rakugi H, Morishita R: IGF Binding Protein-5 Induces Cell Senescence. Front Endocrinol (Lausanne) 2018, 9:53.

51. Allan GJ, Beattie J, Flint DJ: Epithelial injury induces an innate repair mechanism linked to cellular senescence and fibrosis involving IGF-binding protein-5. J Endocrino/2008, 199(2):155-164.

52. Shrine N, Guyatt AL, Erzurumluoglu AM, Jackson VE, Hobbs BD, Melbourne CA, Batini C, Fawcett KA, Song K, Sakornsakolpat $\mathrm{P}$ et al: New genetic signals for lung function highlight pathways and chronic obstructive pulmonary disease associations across multiple ancestries. Nat Genet 2019, 51(3):481493.

53. Ding M, Bruick RK, Yu Y: Secreted IGFBP5 mediates mTORC1-dependent feedback inhibition of IGF-1 signalling. Nature cell biology 2016, 18(3):319-327.

\section{Figures}


A.

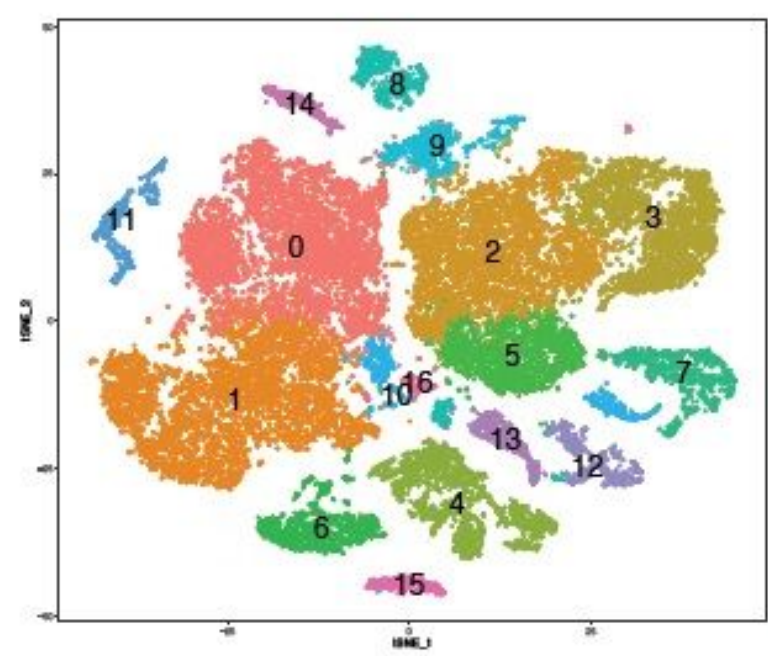

B.

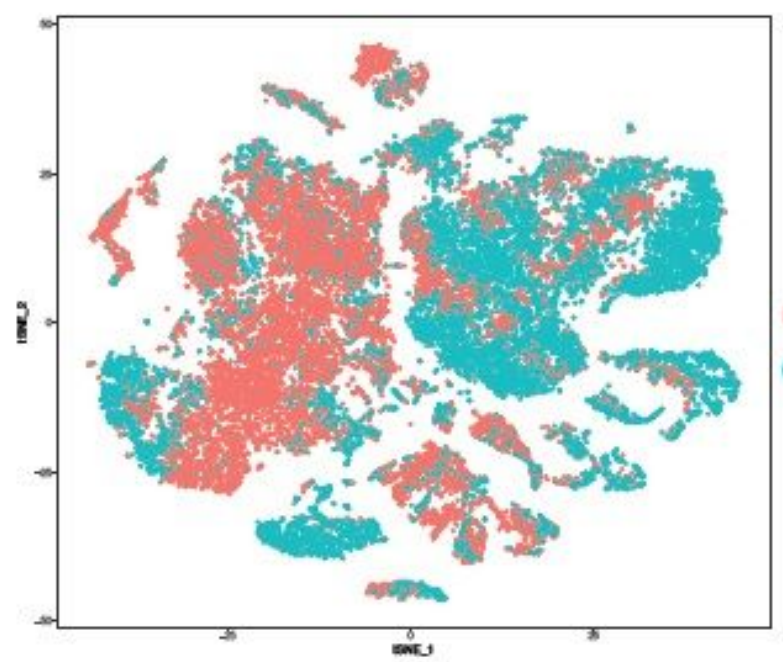

C.

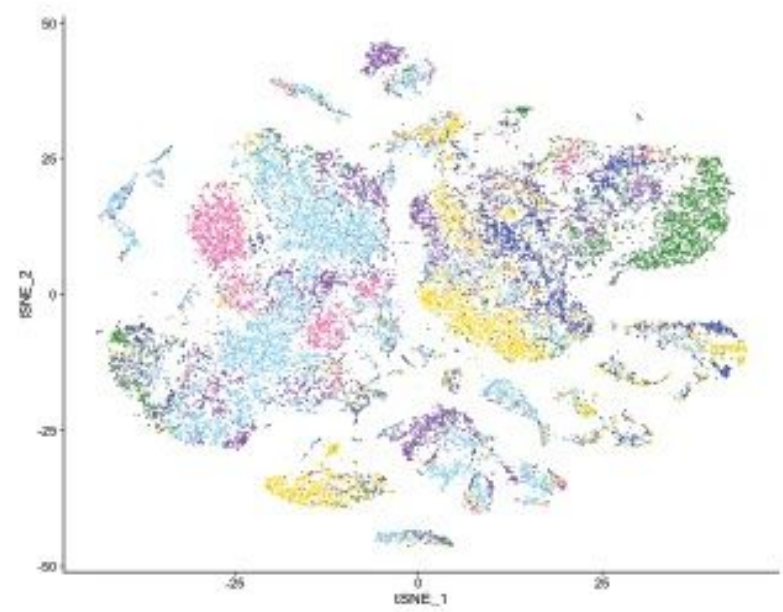

0: FABP4 Macrophage

1: Monocyte

2: Cytotoxic $T$ cell

3: NK cell

4: Endothelial cell

5: $T$ cell

6: B cell

7: Ciliated epithelial cell

8: Alveolar type 2 epitheial cell

9: Low quality T cell

10: Low quality cell

11: Fibroblasts

12: Club epitheial cell

13: Alveolar typ 1 epitheial cell

14: Lymphatic endothelial cell

15: Mast cells

16: Proliferating macrophage

\section{Control}

COPD

Control 1

Control 2

- Control 3

- COPD 1

- COPD 2

- COPD 3

\section{Figure 1}

Single cell RNA sequencing reveals 17 distinct cell clusters from human lungs with severe COPD. A. ScRNA sequencing was conducted using lung parenchymal tissues obtained from 3 nonsmoking normal subjects and 3 patients with severe COPD. t-distributed stochastic neighbor embedding (t-SNE) blots were shown using statistically significant principal components and cells were clustered using an unbiased graphbased clustering algorithm (smart local moving [SLM] clustering, which in total identified 17 distinct types 
of cells, distinguished by color. B. Cells from disease conditions were indicated by different colors. C. Cells from individual subjects were indicated by different colors. D. SLM clustering was made according to distinct gene expression patterns based on various cell types in the lung. E. SLM clustering is shown graphically in feature plots.

A.

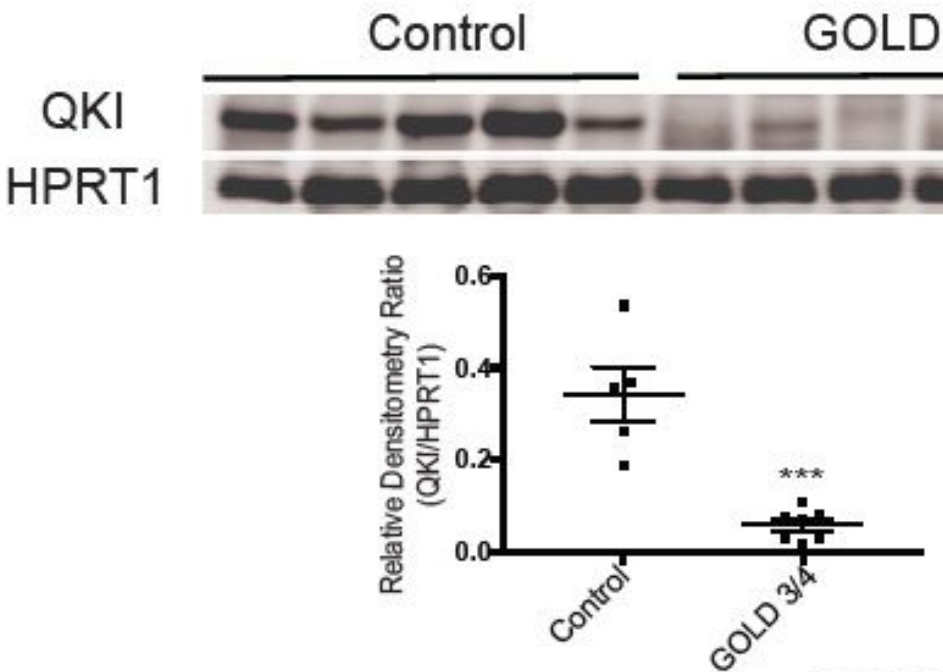

B.

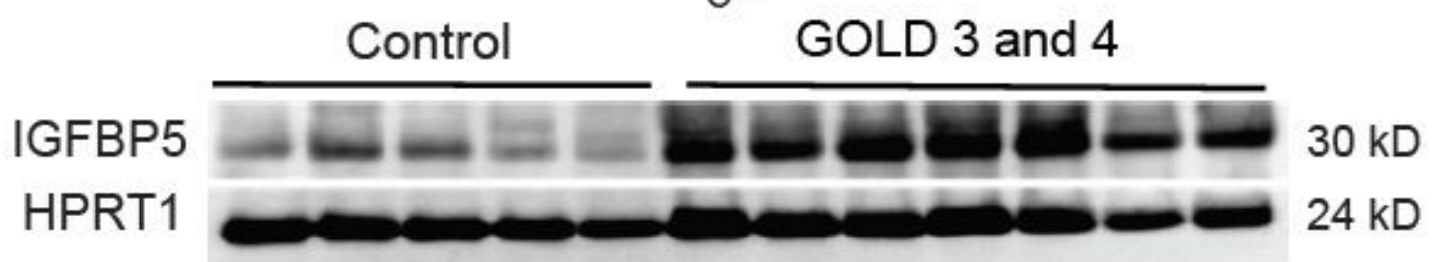

C.
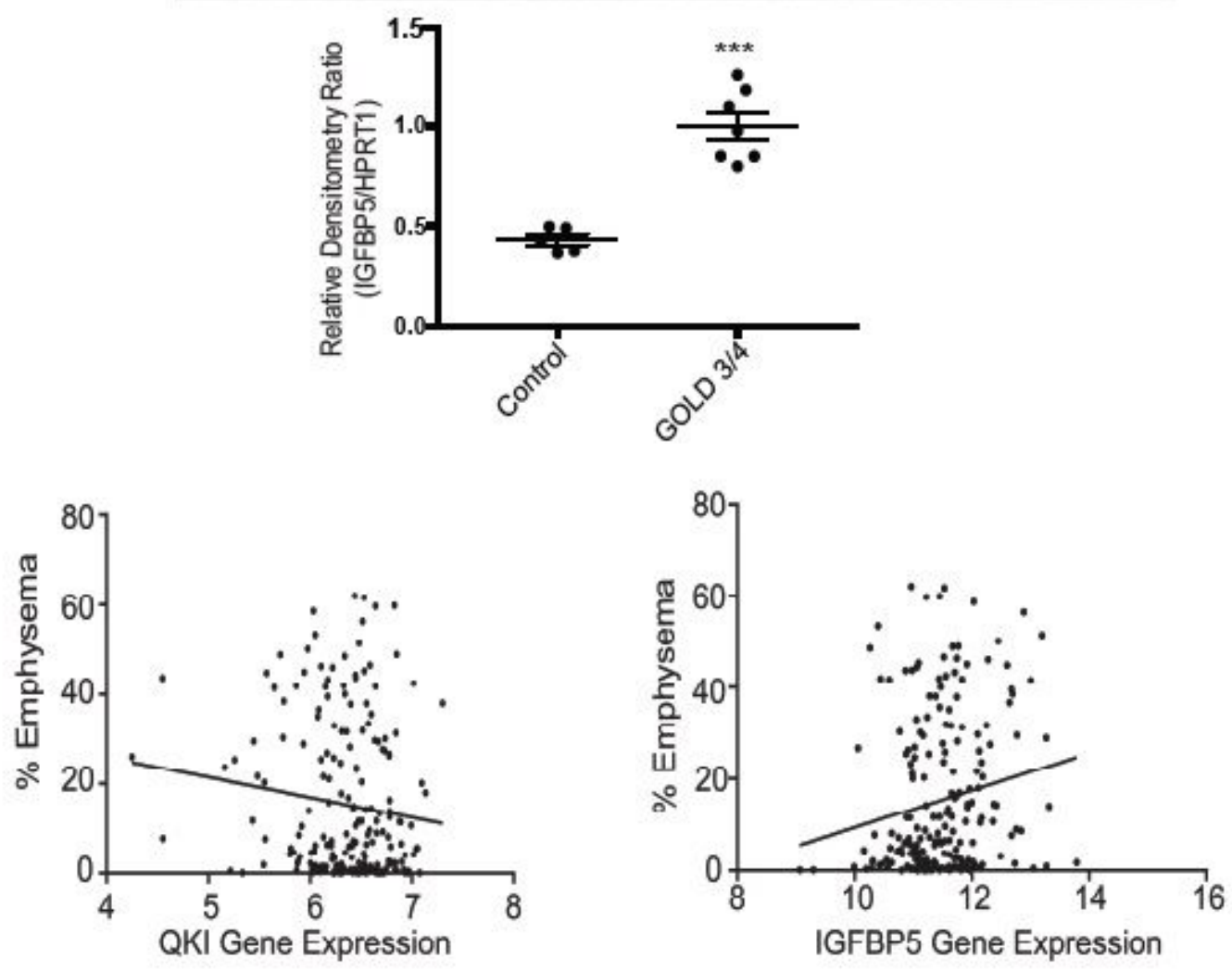

Figure 2 
Quantifying protein levels of some genes significantly altered between normal and COPD lungs. A. Whole parenchymal lung tissues from non-smokers without COPD $(n=5)$ and former-smokers with COPD GOLD stage 3 or $4(n=7)$ were evaluated for protein expression of QKI by immunoblot analysis. The densitometry data (QKI/HPRT1) obtained from individual groups are expressed as mean $\otimes S E M . * \star \star, p$ value $<0.0001$. B. Whole parenchymal lung tissues from the same groups as in (A) were evaluated for protein expression of IGFBP5 by immunoblot analysis. The densitometry data (IGFBP5/HPRT1) obtained from individual groups are expressed as mean $\triangle \mathrm{SEM}$. ***, $\mathrm{p}$ value $<0.0001$. C. QKI and IGFBP5 gene expression in whole lung parenchymal tissue obtained from subjects with various severities of emphysema.

\section{Supplementary Files}

This is a list of supplementary files associated with this preprint. Click to download.

- 2020COPDscRNAseqsupplfigs.pdf

- S1top100genespercluster.xlsx

- S2DEgenesbycluster.xlsx

- S3Positiveenrichemntlogfc0.4padj0.05.xIsx

- S4Negativeenrichemntlogfc0.4padj0.05.xlsx

- S5coreenrichmentgenescampbell.xlsx

- S6DEgenesincelltypesand127GS.xIsx

- S7DEgenesinLTRCandcelltypes.xlsx 